\title{
The Aesthetics of Rupture: Deconstructing Rasa
}

Dr. Siby James

Associate Professor and Research Guide

Dept. of English

St. Thomas College

Pala, Kottayam (Dt.), Kerala, India

sibyjames69@gmail.com

Abstract

Semantic fixity is a transcendental signified. One of the touted aims of literary theory was to topple it. The Indian semantic concept of Vyañjana attempted to do this millennia before. But canonical theories of Rasa established Rasananda as an attainment of absolute coherence and harmony. What this paper calls trans-epistemic praxis is a viable methodology to reclaim the long-lost rupturality (if structurality is resisted, rupturality must be embraced, at least as a neologism) inherent to aesthetics. This is done in a Post-theory context. "Bhanga" (rupturing) leads to "bhangi", aesthetic charm. It is an aporetic textual disruption that leads to the most fertile indeterminacy of meaning. Modern literary theory set out on a debunking and destabilizing mission of liberal humanist tenets, but got hardened into "doxa", crystallized structures and hierarchies. This necessitated a theorizing of theory itself. The chronotope of Post-theory gets foregrounded. A crossing of spatio-temporal boundaries gives us the freedom to site Rasa Theory and Indian Poetics as Post-theoretical. Inter-spaces and intertimes are engendered. Deconstruction and Rasa become heterodoxic knowledges to each other, subverting each other honouring the alterity of the other. This exercise liberates Theory from becoming sclerotic. Orthodoxics and monologisms get flouted. Theory is a story. Story 
is built on the figurality of language. The tropology of language is built on a never-ending desire for signification. This desire never meets with satiation. The concept of "Rati" can be seen as this interminable desire of language. Post-theory is a call to wake up from amnesia, the terrible oblivion regarding the fact that Deconstruction and Rasa are ceaseless streams of reading processes and not rigid and straitjacketed end products. This ruptural aesthetics leads to the rapture of poeisis, the indeterminate significatory process.

Keywords: Transcendental Signified - Vyañjana - Trans-Epistemic Praxis - Bhanga Post-Theory - Asamlakshyakrama vyangya - Chronotope - Doxa - Heterodoxic Abhivyakti - Rati - Differance

Ruptures are everywhere. But ruptures constitute a continuum. This is utterly paradoxical, but aesthetics and literary theory are built on this paradox. Rupture, fragmentation, fissures - these are fundamental to everything including language and discourse. Aesthetics is the study of beauty, and as such it is supposed to be engaged in a search for harmony, unity, plenitude and so on. But as this study attempts to demonstrate, this notion of coherence and totality is a product of what can be called metaphysics - a quest after some transcendental signified that guarantees semantic fixities. Conventional theorists of Indian Aesthetics regard the concept of Rasananda as one such transcendental signified, the attainment of which justifies the stable significatory potential of an artefact. But this is a negation of the inherent textuality of the work of art - the infinite freeplay of signifiers always already at work in the text - which is the cardinal principle behind the concept of Vyañjana. Vyañjana is the infinite semantic possibility of language which functions as the underlying principle of Rasa. This paper attempts to debunk the metaphysics mentioned above from a Post-theoretical application of Deconstruction.

Collating Deconstruction with Rasa in a Post-theoretical scenario might appear a bit bizarre at the outset. The methodology employed here may be designated trans-epistemic 
praxis, i.e. a mutual application of knowledge systems belonging to two entirely dissimilar spatio-temperal settings. Caution has to be given right here: this is not a comparative analysis of Eastern and Western theories at all. As stated at the beginning, this mutual application of knowledge forms is rendered possible through their underlying notion of repture. The fundamental hypothesis that aesthetics is not a study of unity but disruption forms a latent foundation for all knowledge structures. Fissures are everywhere. One synonym for beauty in Sanskrit is "bhangi". Etymologically it comesfrom "bhanga", break or rupture or violation. The study of "bhanga" is aesthetics. Rasasiddhanta and Deconstruction are aesthetic theories in this sense because both concentrate on ruptures, ruptures within systems to be specific. Aesthetics is a system, and as a system it is not immune to disintegration. But this disruption is productive in a strange way. It deconstructively throws open the aporias in texts and systems. Such aporias open the system up to infinite possibilities. Our focus here is on this opening up of the structures of signification.

Rasa is truly aporetic, a chain of never-ending signifiers. The term "asamlakshyakramavyañgya" - rasa realization with imperceptible stages - borrowed from the Dhavani theory bears witness to the undecidability and indeterminacy of linguistic signification in the realization of rasa. This indeterminacy engenders a rapture of poeisis. Poeisis can be explained as a process, a making. Rapture is a result of the realization that the artefact is not a product but a process that is to continue interminably. This can be summed up by saying that the process is from rupture to rapture. Rasananda is another word for this rapture. Ananda is taken here as a concept which flouts all conventional fixities to enter the deconstructive realm where absolute indeterminacy is the only possible state.

For this journey through interminacy we have to situate ourselves within the "chronotopes" of Post-theory. It was Mikhail Bakhtin who introduced the concept of chronotope into theoretical thinking. Bakhtin writes: 
We will give the name chronotope (literally, time-space) to the intrinsic connectedness of temporal and spatial relationships that are artistically expressed in literature. We understand the chronotope as a formally constitutive category of literature (84)

This concept of the chronotope helps us to forge the time-space of Post-theory. There definitely is a "here" and a "there", i.e. India and the West, in spatial configuration for an Indian reader of Western knowledges. There is also, in temporal terms, a division between a "now" and a "then", i.e. the present and the past. Post-theory with its absolute respect for alterity- something that Theory attempted to attain but miserably failed - does not negate the juxtaposition of the spatial "there" with a temporal "then". It is this theoretical gesture that makes the Indian theory of the past - the Rasasiddhanta - Post-theory. An enviable capacity to transcend the borders of time and space is inherent to chronotopicity. Post-theoretical speculations are built on this spatio-temporal porosity.

In Post-Theory: New Directions in Criticism edited by Martin McQuillanet. al. Jeremy Lane presents the chronotope of Post-theory in the following way:

In this case, Post-theory would imply an ability to transcend or move beyond the limitations and weaknesses of 'Theory'. The desire to challenge and transcend that set of theoretical concerns which dominate the intellectual field at any one time is of course entirely laudable. Yet the mode of this transcendence seems to be somewhat paradoxical; what we might term the chronotope of Post-theory would seem typically to involve a moving beyond which is also somehow a return, as Young so tellingly put it, 'to the old certainties of the everyday world outside' (90)

Lane goes on to prove that theory's return is of course there, but it is never to the "old certainties". Post-theory returns to old theories to unravel their uncertainties. Lane is 
actually arguing for a reclaiming of the long-lost impasse of Theory. The very emergence of Theory was meant to unsettle all solidified structures and conventions. But there emerged a "Theory Industry" which effected a crystallization of Theory. A theoretical sclerosis set in the world of Theory. Hence Post-theory.

From Bharata to Jagannatha, i.e. from Natyaśastra to Rasagangadhara, through seventeen centuries, Indian Poetics also underwent this process of crystallization. When Indian Aesthetics became a pedagogical tool to counter the ill-effects of colonization in a post-colonial world, Indian students got exposure only to this already scleroticized body of knowledge. During the last decades of the twentieth century Indian Poetics became highly fashionable in many universities and gained a position of prestige equal to modern literary theory, particularly the extremely radical versions like Deconstruction. But if Indian Aesthetics took almost two millennia to ossify, literary theory needed only two decades for this to happen. Theory, which set out on a debunking and destabilizing mission, became the most sacrosanct acme of canonicity. It is this context that necessitates the conflation of Rasa and Deconstruction.

Lane invokes the concept of "doxa" theorized by Pierre Bourdieu to illustrate his ideas regarding Post-theory. Doxa is a concept where Bourdieu analyses the discursive mechanisms which present all hierarchies as natural and innocent. It is a state so naturalized that it is beyond questioning. A lack of consciousness regarding its very existence is a fundamental trait of doxa. A self-reflexive scrutiny of theoretical doxa is what Post-theory envisages. In other words, it can be called a theorizing of Theory. When Theory is properly theorized, it presents itself to be the locus of conformation of competing discourses. The authenticity and canonicity accorded to any theory, be it Indian or European, is a doxa. It is this doxa that needs to be deconstructed. Post-theory is not to be mistaken as against Theory. It can never be non-theoretical or a-theoretical. It is the most logical culmination of 
theoretical formulations. Hierarchies get toppled here. Doxa causes ideological sedimentation. When this is subverted we get an "inter-space" and an "inter-time" which can successfully accommodate all the alterities of space and time. The elitism within theory which presents the person conversant in the jargon of theory as "knowledgeable" gets erased. The orthodoxy and monologism which repress the plurality and fluidity of discursive formations get into harsh conflict with heterodoxic knowledges which challenge the unitary semantics of language. Etymologically "hetero" is cognate with "itara" in Sanskrit. "Itara" is the other. In a trans-epistemic praxis, Rasa and Deconstruction posit themselves as mutual others, honouring the alterity of the other. Or, in other words, Rasa and Deconstruction assume the status of heterodoxic knowledges within Post-theory.

The legacy of post-structuralism has been elaborately dealt with by Colin Davis in After Post-structuralism. He says that it is a very ambiguous legacy. A legacy will always be ambiguous still to be decided. Had it been unequivocal, no polemics would have emerged regarding what it was and to whom it belonged. Davis goes into Derrida's ideas regarding legacy to justify his point:

Derrida's account of the constitutive ambiguities of legacies concludes with the injunction to read and the warning that it may not be possible. Reading, Derrida suggests, will not settle the legacy once and for all; rather it will keep the dispute alive, providing new resonances with which to preserve and to reinterpret the monuments of our intellectual history (7).

Davis considers stories and story-telling fundamental to all discourses. All theoretical formulations are stories of some sort. Story is a term used here to represent the rhetoricity or figurality of language. In this sense, reading or interpreting a story must be an attempt at unravelling the inherent tropology of language. Language involves only the act of storytelling. The theory of Rasa is a story. So is the theory of Deconstruction. This renders 
possible inter-semiotic readings of stories. All desire, "rati", meets with ultimate fulfilment in most privileged versions of Rasa theory. Abhinavagupta calls this consummation of desire "abhivyakti". But if we make a closer reading of the concept, this story of satiation gets debunked. As an explanation of abhivyakti we can say "AbhivyañjitaSthayin is Rasa". Which means linguistic expressions or enunciations in texts merely give a suggestion or a trigger for the inherent emotion to be roused. Only a ceaseless process of arousal starts here, and no attaining of "śama" or tranquillity is tenable in this context. So "rati" becomes the logic of desire. Since "vyañjana" is a linguistic concept, "abhivyakti", which is derived from "vyañjana", is also a linguistic one. Since desire or "rati" is eternal and not a state of stasis with fulfilled desires, it can be perceived as the Derridean "différance" leading not to a referent but to newer and newer references.

Having seen theories as stories there is no real hitch in establishing their indeterminacy. Story-telling foregrounds the difficulties in establishing the perspicacity of meaning. Stories are simultaneously charming, challenging, irritating and frustrating because they explain too much, but still keep all their secrets to themselves. Infinite possibilities of reading still await the reader. Stories can be, and are, told differently. Post-theory can be viewed as a deviant retelling of Theory. Since we are located within the Indian context, an emplotment of Rasa also can be done within the site of Post-theory. Through their ability to create and maintain obscurities and lacunae, stories have the capacity to lead us to trauma. But this trauma is a fertile and productive one. Making sense of the trauma generated by Theory is actually what Post-theory does. Story and Theory are identical in the challenge to reading they both represent. Theory got depleted of power, and thereby deflated, when this challenge to reading ceased to exist. Theory started churning out stereotypical, hackneyed, tarnished readings of texts through the infinitely repeated activity of theoretical application. That Deconstruction and Rasa are ceaseless streams of reading and are not intended to yield 
rigid and straitjacketed end products was completely pushed to oblivion. Post-theory then is a reminder, a call to wake up from this snare of amnesia. Both Rasa and Deconstruction signify not through their lucid streaks but through their irregularities and blind spots. The attempt in this paper was to show how the borderlines crumble and theory becomes just another literary genre, another name for literariness. Theory is story, theory is rhetoric,theory is poetry. So Rasa theory is not poetics,i.e. the theory of poetry. It is poeisis or the making of poetry. Since the process of making is the only available and accessible entity, Rasa is poetry itself. Philosophy and literature are one in this formulation because both are inhabited by the common factor of figurality. It is on this ground that any Post-theory trans-epistemic practice can be carried out. Identity and difference become mutually contestatory, contaminating and at the same time constitutive categories. The unbridgeable fissure - the gap inherent and among all philosophical systems - within knowledge renders it its aesthetics. And the aesthetics of rupture and the rapture of poeisis exist within the deferral strategy of mutual supplementarity. 


\section{Works Cited}

Bakhtin, Mikhail M. The Dialogic Imagination. Tr. C. Emerson and M Holquist. Austin: Texas UP, 1981.

Davis, Colin. After Poststructuralism: Reading Stories and Theory. London: Routledge, 2004

McQuillanet.al. Post-Theory: NewDirections in Criticism. Edinburgh: Edinburgh U P, 1999. 